\title{
ASO Visual Abstract: TRPV2 Promotes Cell Migration and Invasion in Gastric Cancer via the TGF- $\beta$-Signaling Pathway
}

\author{
Shunji Kato, MD' ${ }^{1}$, Atsushi Shiozaki, MD, $\mathrm{PhD}^{\mathbf{1}}$, Michihiro Kudou, MD, $\mathrm{PhD}^{\mathbf{1}}$, Hiroki Shimizu, MD, $\mathrm{PhD}^{\mathbf{1}}$, \\ Toshiyuki Kosuga, MD, $\mathbf{P h D}^{1}$, Takuma Ohashi, MD, $\mathbf{P h D}^{1}$, Tomohiro Arita, $\mathbf{M D}, \mathbf{P h D}^{1}$, \\ Hirotaka Konishi, MD, PhD ${ }^{1}$, Shuhei Komatsu, MD, $\mathbf{P h D}^{1}$, Takeshi Kubota, $\mathbf{M D}$, $\mathbf{P h D}^{1}$, \\ Hitoshi Fujiwara, MD, PhD ${ }^{1}$, Kazuma Okamoto, MD, PhD ${ }^{1}$, Mitsuo Kishimoto, MD, PhD $^{2}$, \\ Eiichi Konishi, MD, $\mathbf{P h D}^{3}$, and Eigo Otsuji, MD, $\mathbf{P h D}^{1}$ \\ ${ }^{1}$ Division of Digestive Surgery, Department of Surgery, Kyoto Prefectural University of Medicine, Kyoto, Japan; \\ ${ }^{2}$ Department of Pathology, Kyoto City Hospital, Kyoto, Japan; ${ }^{3}$ Department of Pathology, Kyoto Prefectural University of \\ Medicine, Kyoto, Japan
}

In this study, TRPV2 promoted tumor migration and invasion via the transforming growth factor beta (TGF- $\beta$ )signaling pathway, and the strong expression of TRPV2 was associated with a worse prognosis for the patients with gastric cancer. (https://doi.org/10.1245/s10434-021-1 1132-5).

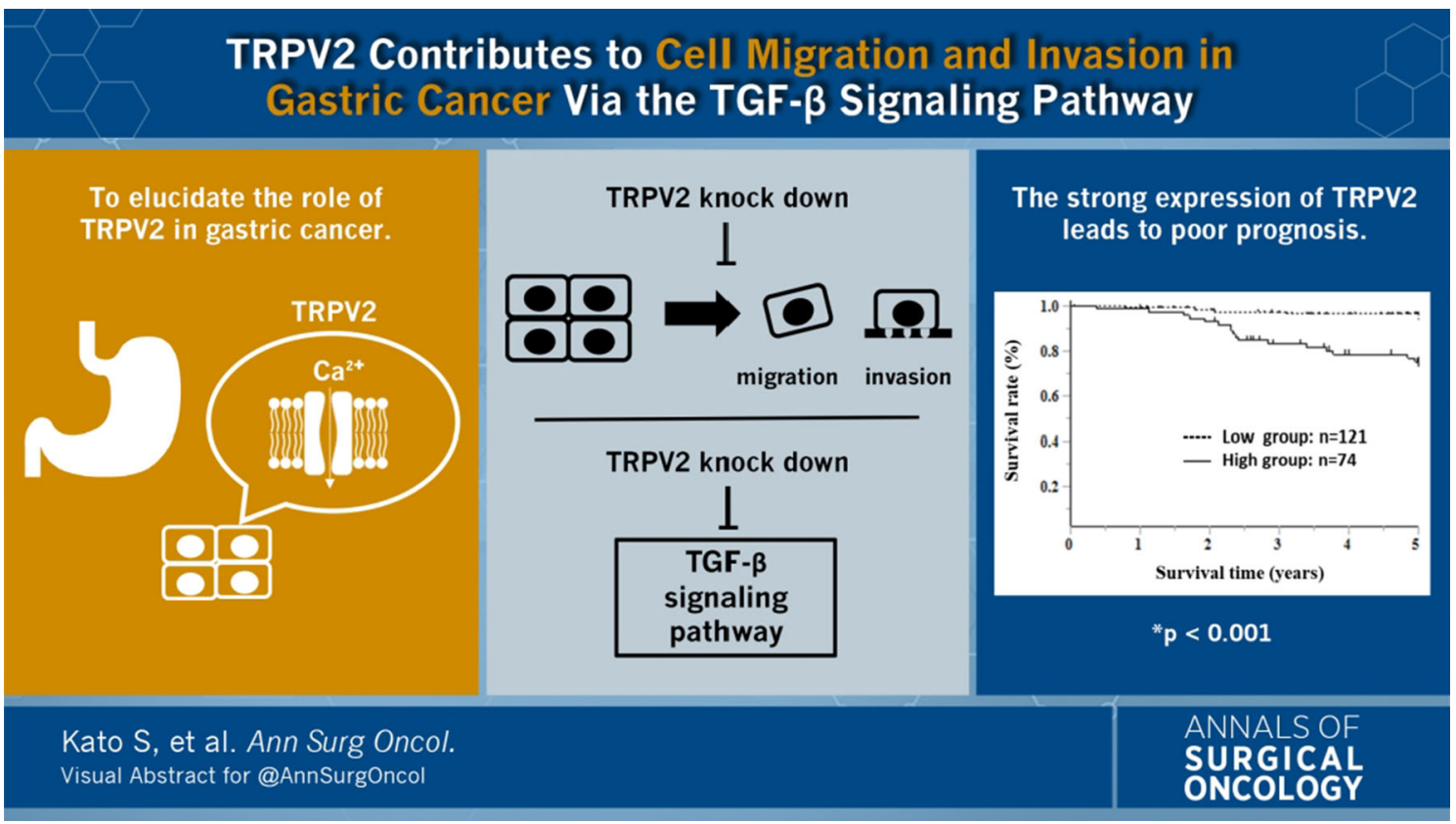

Shunji Kato and Atsushi Shiozaki have been contributed equally to this work

(C) Society of Surgical Oncology 2022

A. Shiozaki, MD, $\mathrm{PhD}$

e-mail: shiozaki@koto.kpu-m.ac.jp
DISCLOSURES There are no conflicts of interest.

Publisher's Note Springer Nature remains neutral with regard to jurisdictional claims in published maps and institutional affiliations. 